\title{
Correction to: Co-treatment with rivastigmine and idalopirdine reduces the propensity for falls in a rat model of falls in Parkinson's disease
}

\author{
Ajeesh Koshy Cherian $^{1} \cdot$ Aaron Kucinski $^{1} \cdot$ Ryan Wu $^{1} \cdot$ Inge E. M. de Jong $^{2} \cdot$ Martin Sarter $^{1}$ \\ Published online: 25 October 2019 \\ (C) Springer-Verlag GmbH Germany, part of Springer Nature 2019
}

Correction to: Psychopharmacology https://doi.org/10.1007/s00213-018-5150-y

After publication of this paper, the authors determined that the "Acknowledgments" section was omitted. Below is the "Acknowledgments" statement.

Acknowledgments We wish to acknowledge the technical assistance of Lisa Waldman.

Publisher's note Springer Nature remains neutral with regard to jurisdictional claims in published maps and institutional affiliations.

The online version of the original article can be found at https://oi.org/ 10.1007/s00213-018-5150-y

\footnotetext{
Martin Sarter

msarter@umich.edu

1 Department of Psychology, University of Michigan, 530 Church

Street, Ann Arbor, MI 48109, USA

2 Division of Neurodegeneration, H. Lundbeck A/S, Valby, Denmark
} 